\title{
Reflexiones sobre la importancia de una educación holística dentro de un proyecto de comunidad sostenible
}

\author{
Gibran Cervantes
}

Mi nombre es Gibran Cervantes, soy padre de tres hermosas niñas, empresario, músico de profesión y un apasionado en temas de conservación de la naturaleza. Hace 15 años después de perder la estabilidad de mi salud a raíz de un accidente, decidí reorientar el rumbo de mi vida para comenzar a formarme a nivel profesional de manera independiente, fuera de las instituciones, ya que mi manera de aprender no se ajustaba a las estructuras educativas convencionales y no despertaron gran interés en mí en ese entonces. Por otra parte, mi estado físico no me permitía asistir con regularidad a la universidad. De este modo decidí comenzar un viaje de reconstrucción. Gracias al apoyo de amigos y de colegas pude desarrollarme en distintas áreas y entendí la manera en que debía articular distintas disciplinas para lograr la integración de un proyecto polifacético, el cual hoy con gusto quiero compartirles.

Desde el año del 2006 me preocupan y ocupan los temas de la educación holística, la cohesión social y el sueño de una comunidad sostenible. Este camino me ha llevado a investigar sobre temas de educación consciente, de bio-construcción, de agricultura orgánica (biodinámica y permacultura) y de desarrollo social. Verdaderamente me apasiona aprender cosas nuevas todos los días; llenar mis manos de tierra. Estoy convencido que esta forma de educación tiene mucho que aportar a las nuevas generaciones en materia de sustentabilidad y cohesión social. Acompañado de un equipo entusiasta, los sueños fueron tomando forma y ahora, como presidente y director de Bios Comunidad Sustentable, quisiera compartir brevemente esta experiencia centrándome en algunos de los proyectos en los que hemos trabajado y realizado.

El enfoque educativo actual nos deja un aprendizaje sin experiencias, sin una reflexión, que nos permita cuestionar el sentido lógico y la utilidad de los acontecimientos dentro de nuestras vidas. Es decir, a partir de este enfoque actual solo repetimos y obedecemos el mandato histórico y cultu- 
ral que nos ha sido enseñado, sin cuestionarnos si la manera cómo hacemos las cosas es la adecuada, si es funcional o si puede hacerse de otra manera para lograr vivir mejor. Yo mismo viví mis años escolásticos mediante un proceso de "aprendizaje" basado en la memorización por lo que me han surgido ciertos interrogantes: ¿La manera en que vivimos en nuestro hogar y nuestra tierra, es adecuada y respetuosa con la vida misma? ¿La construcción de una sociedad basada en el consumo constante sin límites y la cruda competencia sin respeto por el otro, está funcionando para ayudarnos a desarrollarnos como seres humanos? ¿La falta de una cohesión social profunda y vínculos sagrados con la tierra y nuestra comunidad nos está permitiendo evolucionar como seres conscientes para alcanzar una vida plena y digna? ¿La educación formal nos está ayudando a alcanzar este objetivo?

A un ritmo muy acelerado, cada vez nos alejamos más de nuestra esencia y de la magia de la vida, de la existencia divina y del centro del corazón humano. El simple hecho de entrenar a los niños mediante conceptos y datos para que puedan lograr conseguir notas para un examen, un lugar en el aula de la escuela, en alguna universidad o un puesto en una empresa, es sencillamente una rutina que nos está llevando a un deterioro en el proceso natural de autoconstrucción del ser humano, de la auto observación y del auto desarrollo y esto nos pone frente a un laberinto sin salida con pocas alternativas dentro de nuestra sociedad moderna. El automatismo que se observa en la actualidad, es el resultado de la educación arcaica que hemos recibido estos últimos años. Siguiendo a Boff (2002) estamos olvidando "El cuidado esencial, la ética de lo humano y la compasión por la tierra" (Boff, 2002, p. 164).

Por consecuencia estamos reprimiendo las maravillosas capacidades que tenemos los humanos de expandir nuestra conciencia y evolucionar hacia un mundo con mejores posibilidades para todos. De hecho, existen dos palabras que, aunque similares, nos ofrecen dos conceptos diferentes que nos permiten apoyar esta reflexión: Educare versus Educere.

Educare (proviene del latín) y significa llenar de conocimiento al alumno, introducir conceptos, por parte de un adulto o profesor, formar al educando. Educere por su parte significa "apoyar en el proceso individual de cualquier persona para lograr sacar la luz de su ser interior hacia el mundo", (Bass \& Good, 2004) De esta segunda palabra y su significado nació la iniciativa de comenzar con una propuesta educativa holística e integral, tomando como base la filosofía Montessori, adaptándonos a nuestra realidad actual y condiciones sociales, económicas y ambientales de nuestra zona y comunidad local. De estas reflexiones nace el proyecto BIOS Lila, con una misión especifica: Inspirados en la filosofía Montessori y en programas vivenciales agroecológicos, buscamos fomentar el desarrollo integral de los talentos individuales de los niños-tanto a nivel 


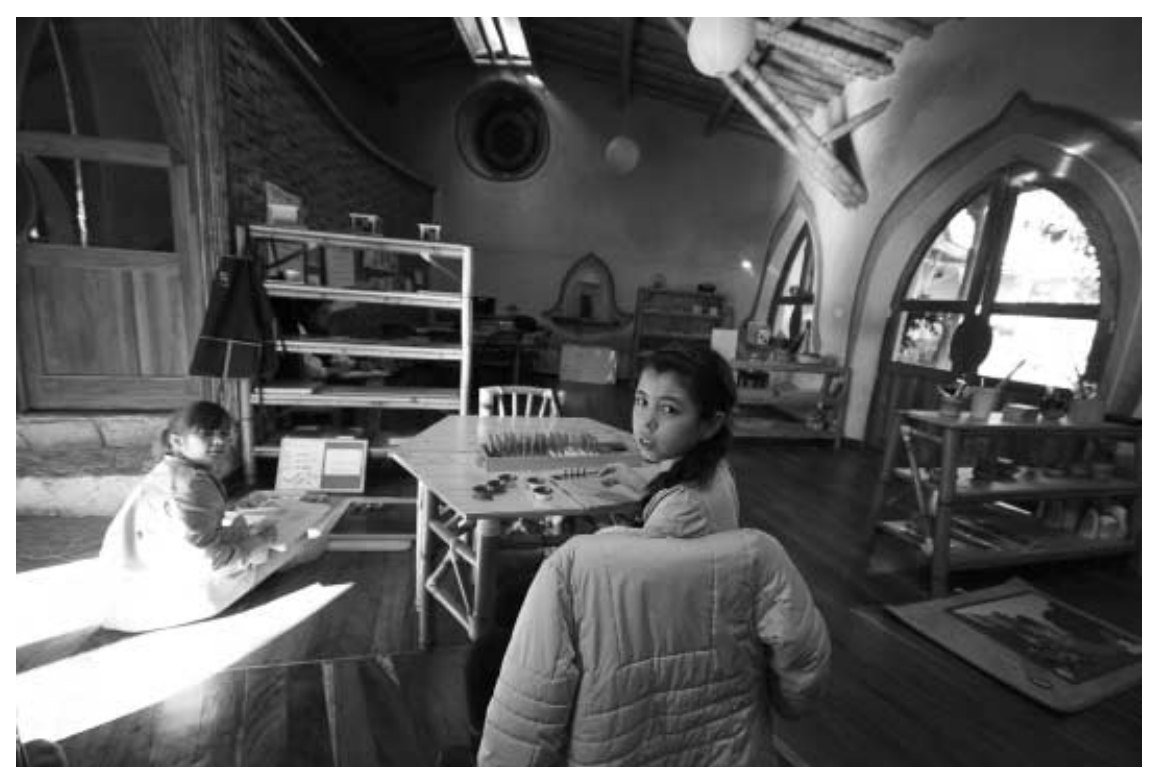

Figura 1 - Ambiente Montessori

intelectual como artístico y espiritual-despertar su interés natural por el conocimiento, el respeto de sí mismo, su entorno y su comunidad; y mostrarles el uso sostenible de los recursos naturales.

En BIOS Lila intentamos trabajar desde la raíz del problema, ofreciendo un ambiente preparado para que se dé, de manera natural, la libre elección, despertando la curiosidad personal por explorar este camino de descubrir el conocimiento de todas las áreas; como lo llama Maria Montessori, "Educación Cósmica" (Montessori, 1998).

Las experiencias nos dan muchas posibilidades de aprehender, de encarnar por uno mismo a través del hacer, un entendimiento propio, un "hacerlo por mí mismo, descubrirlo por mí mismo". Oliendo, tocando, sintiendo, moviendo, eligiendo, haciendo uso de las formas, las texturas, los libros, los números, los cuentos, las plantas, la historia, la tierra. Es por esto que el proceso normal de aprendizaje viene de lo concreto a lo abstracto, así que solamente ofrecemos las herramientas para que esto se dé, de manera espontánea y por consecuencia se detone el ejercicio del conocer.

Metiendo las manos en la tierra, sembramos esperanza, trabajando con los niños en huertos de traspatio que proveen a la escuela de hortalizas para distintos fines, descubren la diversidad de organismos que existe en el subsuelo, los cuales ayudan a mantener un ambiente fértil que permite a las plantas nutrirse y desarrollarse óptimamente. En este proceso los niños conocen y experimentan el ciclo completo de producir sus propios alimentos y cosecharlos, respetando los ciclos biológicos. 


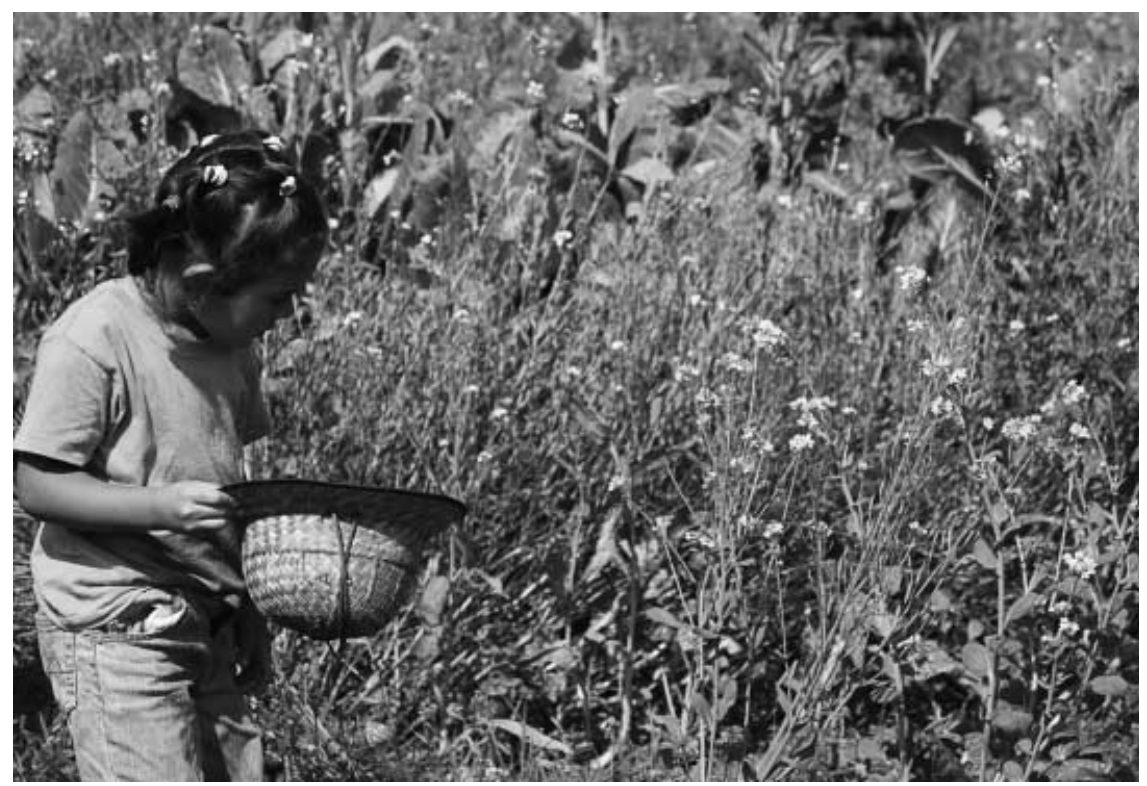

Figura 2 - Cosechando flores

La escuela no es una "escuela común" es un centro de reconstrucción social al servicio de la comunidad, en donde pueden compartir anhelos las familias, en donde se cuestionan y convergen distintos puntos de vista que nutren a este sistema. Somos una red de familias vinculadas a un proyecto educativo responsable para con nuestros hijos, construyendo un futuro que ningún gobierno nos puede ofrecer, una seguridad social basada en la autonomía y la gobernanza. La escuela se ha convertido en un campo de energía que reúne a personas, buscando una vida más conectada con los procesos naturales de la vida, de la tierra, y de las estaciones.

La bio-construcción de la escuela nos permitió ligar temas como el refugio y la tierra como elemento constructivo de hogares y ambientes saludables. Este espacio se ha convertido en un icono de la bio-construcción en Coatepec, y al mismo tiempo es un refugio para nuestros niños, con colores hermosos de tierras recolectadas en los alrededores de la zona. Todos los materiales que se usaron son materiales naturales: bambú, pacas de paja, tierra, piedras, cal, madera. En su mayoría se usaron materiales locales de productores cercanos a la escuela para fomentar un impulso a la economía local. Muchos de los niños y algunas familias participaron en algunas fases de construcción de este espacio y me atrevo a decir que es un regalo que perdurara en su corazón por siempre, un recuerdo y una semilla que germinará en el momento en que las condiciones de alguna manera sean adecuadas. 


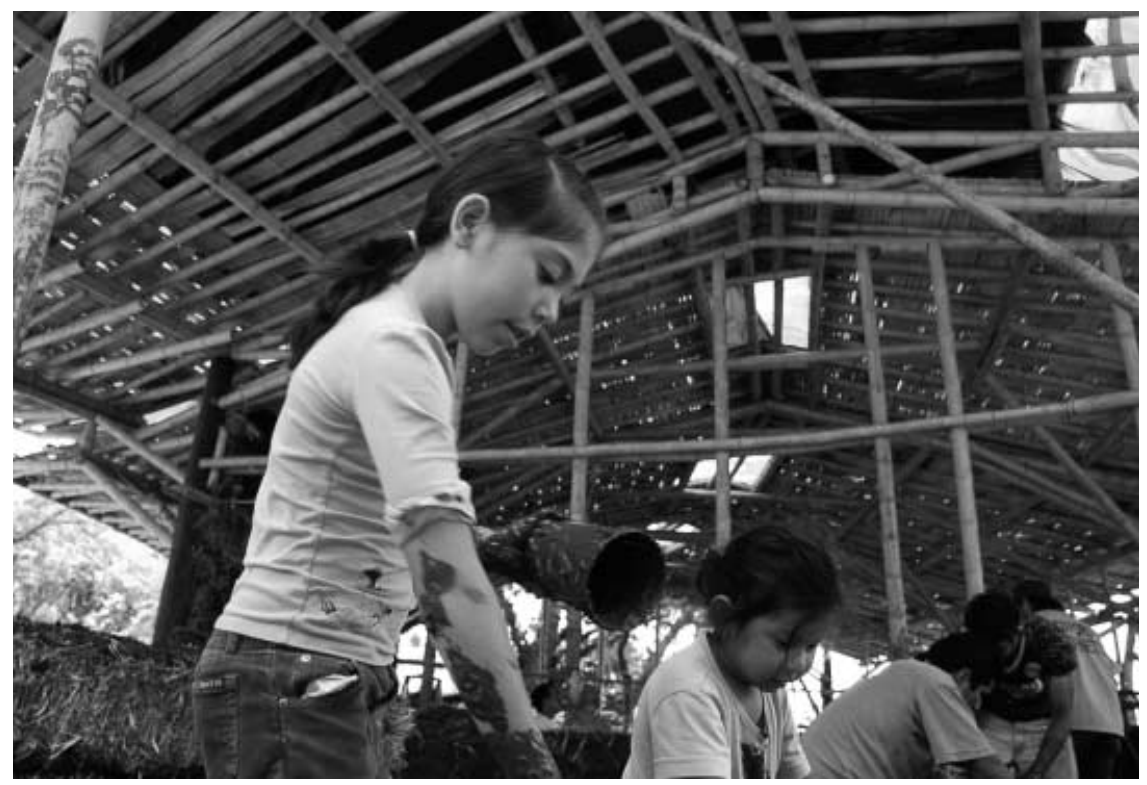

Figura 3 - Construyendo con Cob y pacas de paja I

La utilización de materiales regionales no solo nos permitieron un ahorro en combustible en la transportación sino que además, al ser utilizados en su estado natural/crudo, nos permitieron prácticamente eliminar la generación de emisiones de bióxido de carbono, reduciendo con esto nuestra huella ecológica. El edificio de Bios Lila no liberó bióxido de carbono a la atmosfera en su construcción, su impacto ambiental es muy bajo, se respira un ambiente natural al adentrarse en sus aulas con texturas hermosas y aromas a paja. Las construcciones convencionales de cemento o tabique recosido generan muchas emisiones y su contaminación es muy alta. Dimitri Papalexopoulos gerente director del Cemento Titan dice: "No importa lo que se haga, la producción de cemento siempre libera dióxido de carbono. No se puede cambiar el proceso químico, así que no se logra cortes espectaculares en las emisiones", (Arquitectura en construcción).

Gracias a esta iniciativa se recuperaron técnicas de construcción con tierra que ya no se tenía conocimiento del uso de estos materiales y sus posibilidades arquitectónicas. Se organizaron cursos con arquitectos y maestros albañiles para re-aprender cómo es que la mecánica de la tierra y el bambú trabajan, para leer las posibilidades de estos materiales y así recuperar nuestra autonomía respecto a la construcción consciente de nuestros hogares, y se crearon varios grupos de trabajo en bio-construcción que ahora dan servicio por su cuenta a terceros. El propósito de este proyecto ha sido el de concientizar a las personas sobre la importancia 


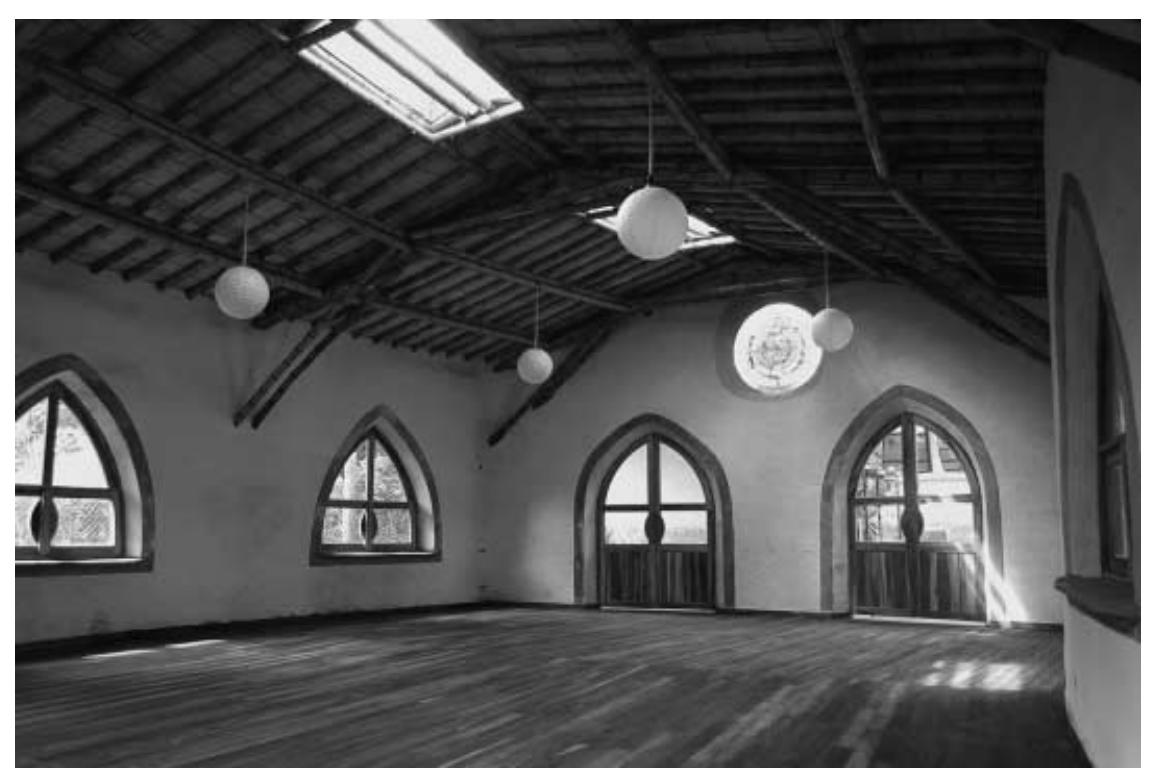

Figura 4 - Ambiente de escuela bio construída

que tienen los saberes en el lugar que estamos habitando (i.e., casas materiales de construcción) y sobre cómo impacta a nuestro entorno social y ecológico, a nuestra comunidad, a la cultura de nuestro pueblo, a nuestra economía, a nuestra salud y a la de nuestras familia.

A 20 minutos de la escuela, el proyecto cuenta con un espacio productivo de 25 hectáreas de alimentos llenos de vida: Café, hortalizas biodinámicas, derivados de productos de cabras, áreas de conservación de bosques y áreas de conversión de potreros, en donde estamos trabajando en su reforestación. Se trata del Cafetal el Equimíte (rancho agroecológico (biodinámico) que da la bienvenida a los niños de la escuela cada tres semanas para realizar prácticas de agroecología y de eco-pedagogía en este ecosistema lleno de vida.

La agricultura biodinámica ${ }^{1}$ nos permite mantener el impulso vital de este lugar, trabajando con los campesinos lugareños, familias cafetaleras de años de tradición, jóvenes que ya se habían rendido ante la frustración de trabajar en el campo y la paga injusta por el intercambio de su trabajo, encontrando una posibilidad para su futuro, generando la cimentación para una socialización productiva (Rudolf, 2009).

Los niños de BIOS Lila están observando todos estos procesos desde pequeños. Los colaboradores del Equimíte trabajamos para sembrar cuantas semillas sea posible en estos niños y así darles una visión distinta de un mundo que podemos mejorar. Cosechamos café y hortalizas 


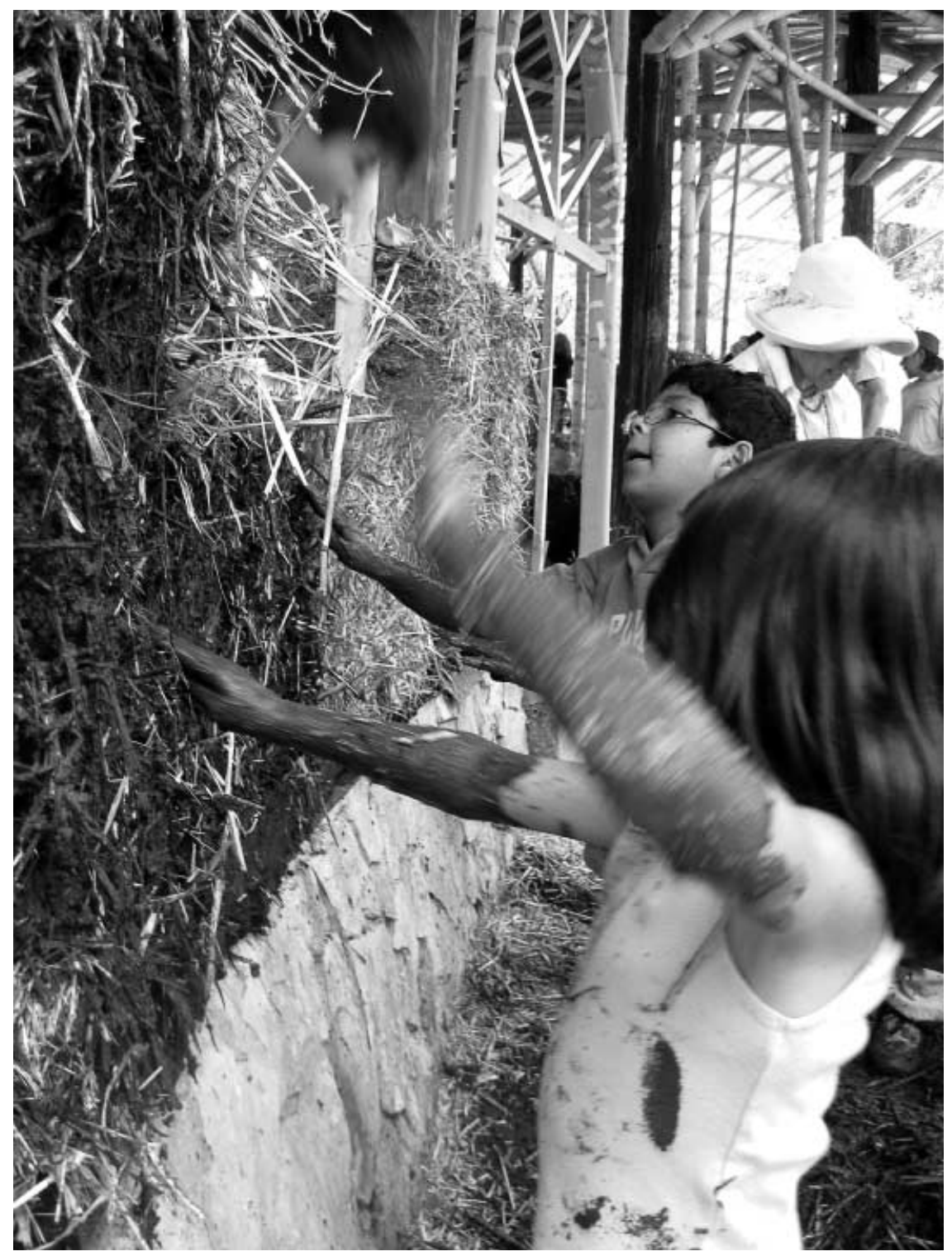

Figura 5 - Construyendo con Cob y pacas de paja II

sin agroquímicos ni pesticidas, con semillas de polinización abierta, no modificadas genéticamente, ordeñamos las cabras, hacemos pan, hacemos compostas, producimos plantas medicinales, sembramos, cuidamos de los animales, aplicamos preparados biodinámicos (homeopatía) a los cultivos, "sanar la tierra para sanar al hombre" (Le Noir). 


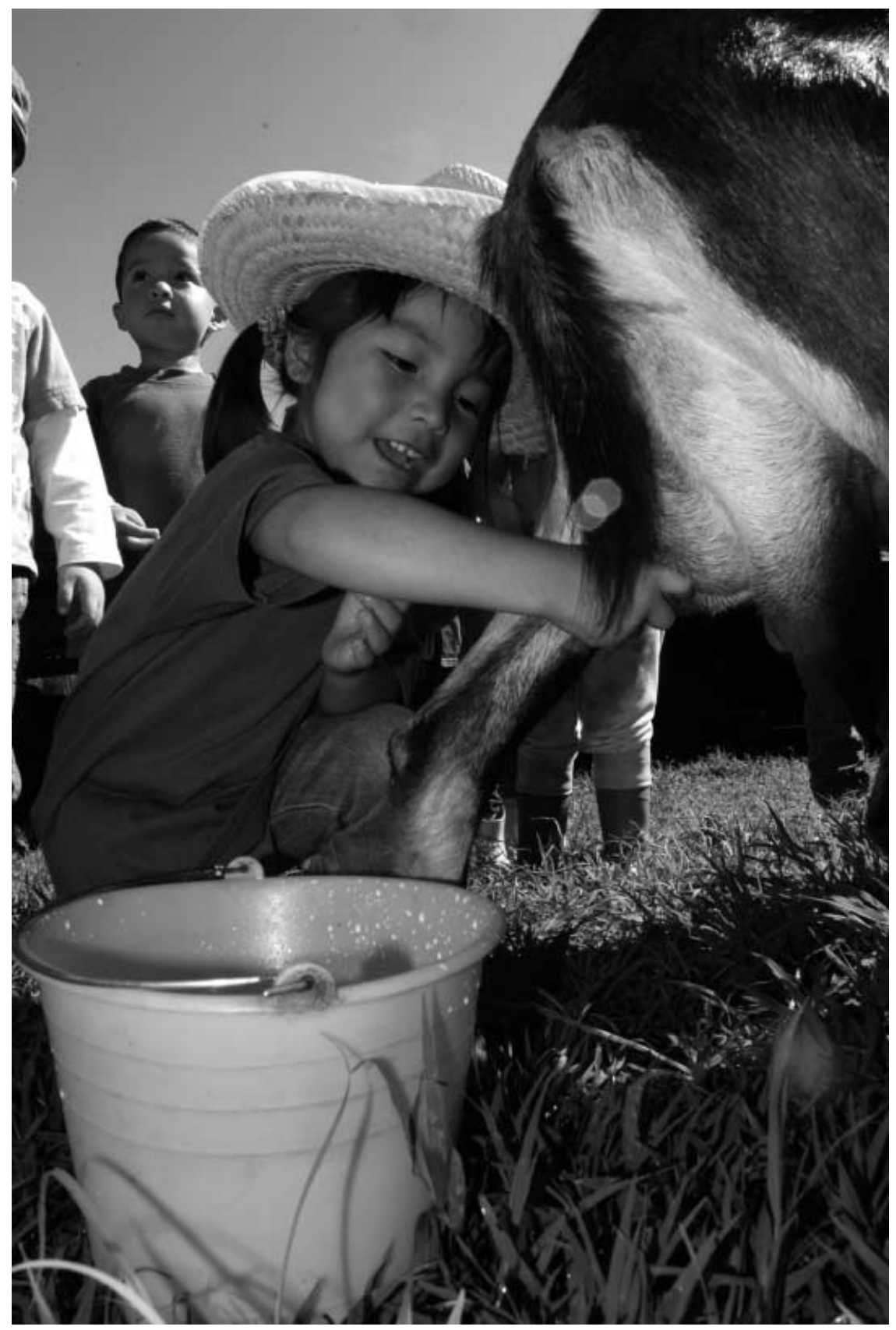

Figura 6 - Ordeñando cabras en el Equimite 


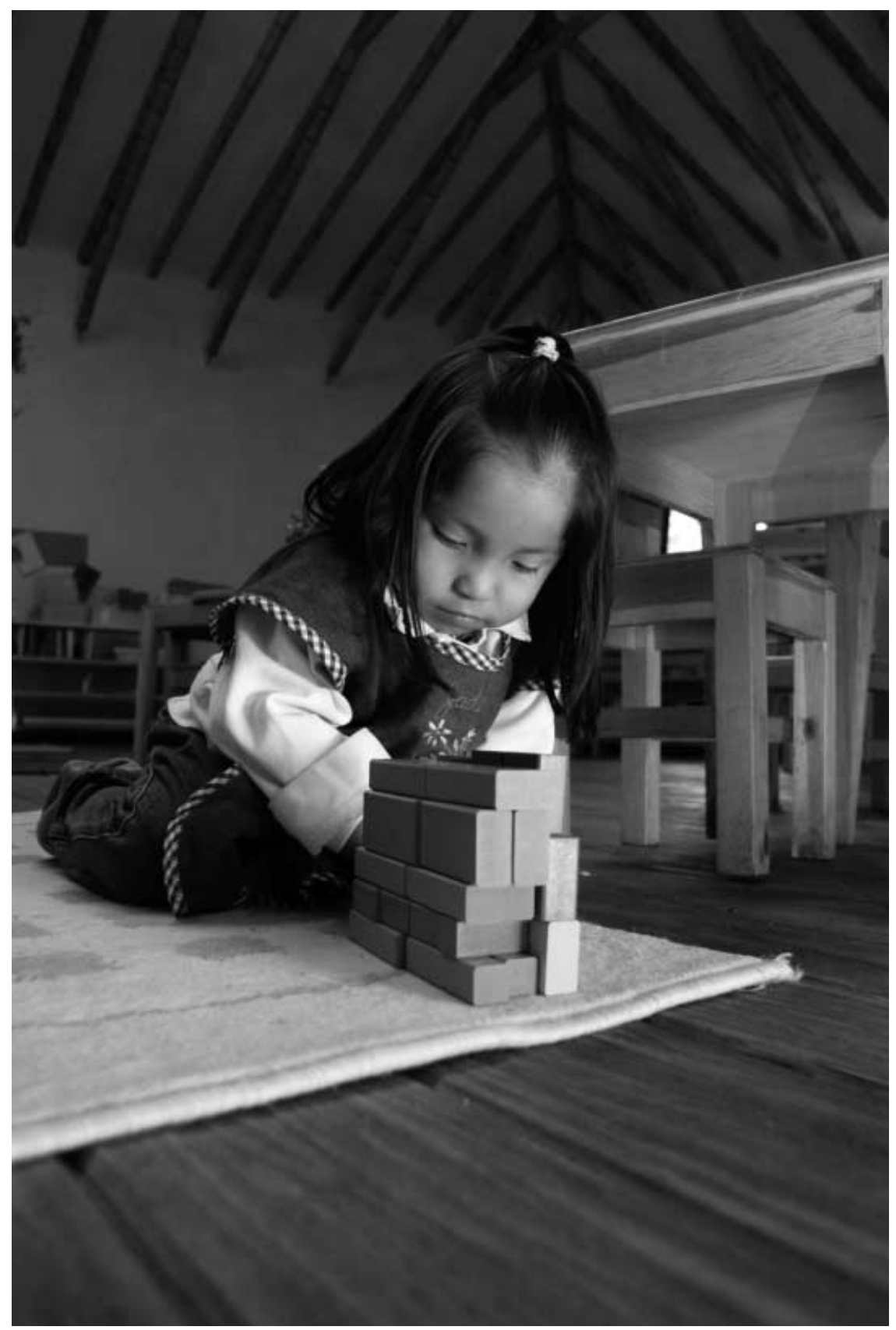

Figura 7 - Niña con material Montessori 
Por otra parte pero ligado a este proyecto, estamos trabajando en el fortalecimiento de una red de consumo responsable que surte de verduras biodinámicas y orgánicas a 30 familias semanalmente. Durante dos años hemos podido mantener una producción estable para garantizar el abastecimiento a todas estas personas. Esta es otra acción para generar un cambio alimenticio estructural, el despertar de las personas a una concientización sobre el buen comer y su relación con la vitalidad y derecho de

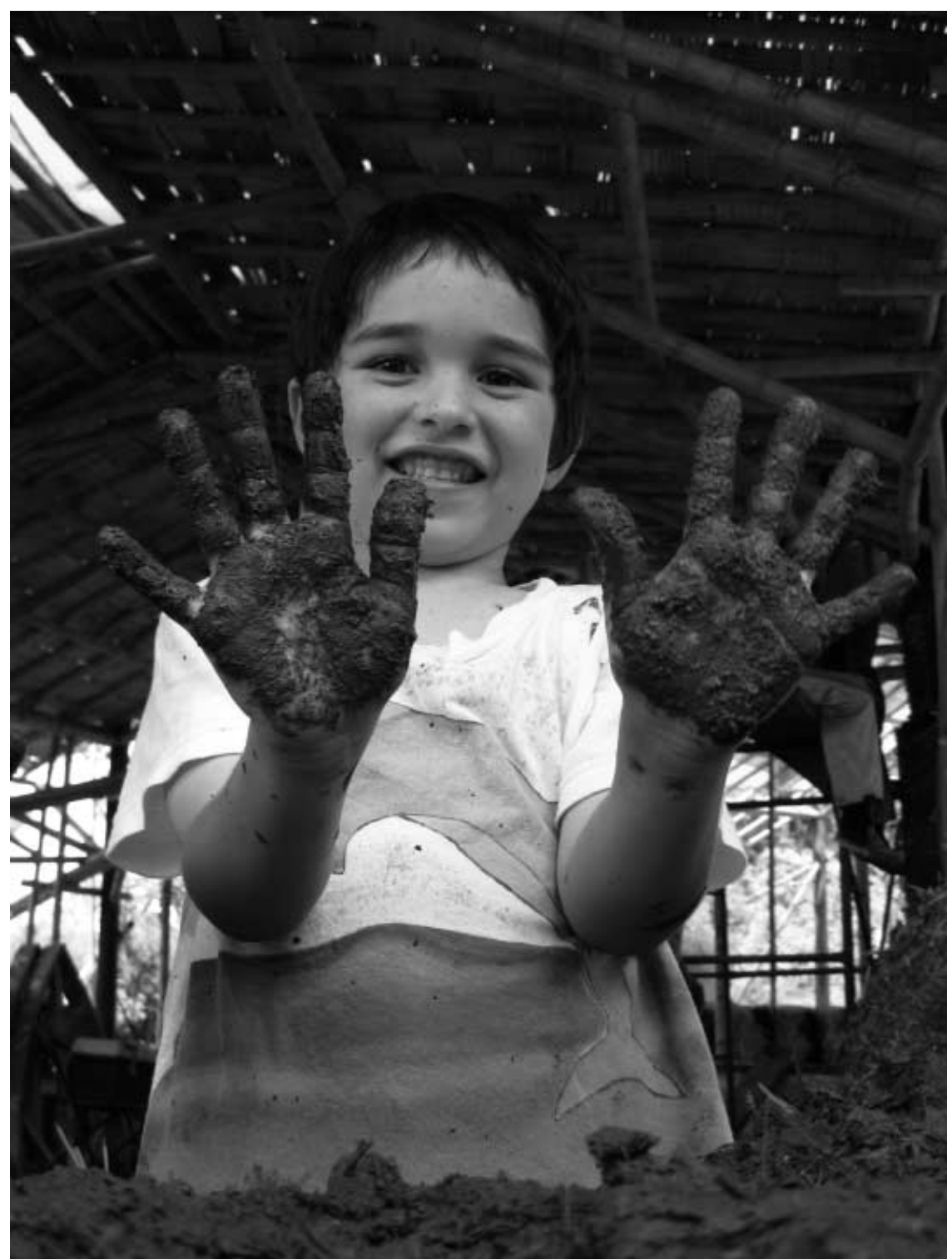

Figura 8 - Manos con lodo 
vivir saludables. La comunicación y participación consciente de las familias es la clave para fortalecer de fondo proyectos con estas características. En el Cafetal el Equimíte fomentamos la vida, cuidamos la tierra, la microbiología que vive en los suelos que nos dan de comer, el agua y toda expresión de vida que ahí observamos.

Quiero concluir explicando que somos un grupo de empresas con la intención de generar un impacto social, económico y ambiental en la comunidad de Coatepec, Veracruz, trabajando con seis pilares básicos que tienen que ver con los fundamentos de la vida: (a) educación holística e integral; (b) refugio (Bio-construccion); (c) alimentación (agricultura biodinámica); (d) conservación (paisaje productivos y bosques secundarios); (e) desarrollo comunitario (red de consumo responsable, centros de capacitación para comunidades locales en producción biodinámica de alimentos y bio-construcción; (f) y medicina (producción de plantas medicinales y su procesamiento). ${ }^{2}$

Así, Bios comunidad sustentable es la unión de todos estos proyectos en donde trabajamos por reconstruirnos como personas, para aprender a organizarnos de una manera distinta, a darle valor a nuestra comunidad, a nuestra tierra, a nuestros niños y familias, a nuestras plantas medicinales y nuestros alimentos, a nuestras casas de barro.

Su interés y comentarios sobre este artículo serán siempre bienvenidos a la siguiente dirección electrónica: gibran@bioslila.com.

\section{NOTAS}

1. Para mayor información consúltese http://www.demeter.net

2. Pueden consultarse nuestros sitios web: http://www.bioslila.com y http:// equimite.wordpress.com.

Algunos Proyectos que me han inspirado:

Sekem Group: http://www.sekem.com

Valle la Paz :http://www.lapazpharma.com/web/

La escuela de los descalzos Bunker Roy: http://www.ted.com/talks/

bunker_roy?language $=\mathrm{es}$

The Green school: http://www.greenschool.org

Paty Ruiz: http://www.youtube.com/watch?v=1NUSg0rHRE0

\section{REFERENCIAS}

Architectura en Construcción. (2013). Un sitio de crítica constructiva, medio ambiente y percepción de la ciudad, para expertos y novatos. Descargado de http://arquitecturaenconstruccion.blogspot.mx/2007/10/concreto-contami nante.html 
Bass, R., \& Good, J. W. (2004). Educare and Educere: Is a balance possible in the educational system? The Educational Forum, 68, 161-168.

Boff, L. (2002). El cuidado esencial. Madrid: Editorial Trotta.

Le Noir, D. Valle La Paz: Sanar la tierra para sanar al hombre. Descargado de http://www.lapazpharma.com

Montessori, M. (1998). Educar para un mundo nuevo. Buenos Aires: Longseller, S. A.

Steiner, R. (2009). Curso sobre agricultura biológico dinámica. Madrid: Rudolf Steiner. 